\title{
Views of the person with dementia
}

Julian C Hughes Newcastle General Hospital, Nerwcastle upon Tyne

\begin{abstract}
In this paper I consider, in connection with dementia, two views of the person. One view of the person is derived from Locke and Parfit. This tends to regard the person solely in terms of psychological states and his/her connections. The second view of the person is derived from a variety of thinkers. I have called it the situated-embodied-agent view of the person. This view, I suggest, more readily squares with the reality of clinical experience. It regards the person as embedded in a history and culture. The human person is also an embodied agent. I contend that this view encourages a more appropriate approach towards the ethical issues that arise in dementia and towards people with dementia.

(Fournal of Medical Ethics 2001;27:86-91)
\end{abstract}

Keywords: Person; dementia; advance directives; psychological phenomena; narrative; end of life

\section{Introduction}

Dementia raises crucial questions about the person. A patient with dementia tells me she can no longer feel, it's as if she is not real. A spouse tells me his wife with dementia is a different person from the one he married. Some say that in severe dementia the person is lost. Is it right to think that dementia destroys the person as it destroys the brain?

In this paper I shall consider two views of the person. I shall favour one over the other on the basis of clinical experience. The view I favour is the situated-embodied-agent view of the person. To anticipate, this view regards the person as embedded in a history and culture. The person is a human agent too, with a particular form and capable of acts which have a significance within a certain context. The alternative view is derived from Locke and Parfit. According to this view, to be a person is precisely to be capable of certain sorts of mental activity. In particular, to be a person is to have enough psychological continuity and connectedness. The view taken has important ethical consequences. For a person must be respected, afforded dignity and protection under the law; a person, as a person, has a call on our concern.

My argument is as follows:

1. To be justifiable our notion of the person must square with clinical experience;

2. The Locke-Parfit (LP) view of the person squares with only a circumscribed account of clinical experience;

3. The situated-embodied-agent (SEA) view of the person squares with a richer account of clinical experience;
4. Therefore, the SEA view of the person, over against the LP view, is more justifiable.

I shall, of course, expand the premises of this argument. It is worth noting at the outset, however, that the conclusion of the argument itself has implications. There are philosophical implications: for instance, to do with our understanding of the mind. And there are practical implications: the conceptual view we have of the person will affect the care we are prone to give to people with severe dementia.

\section{The person and clinical experience}

My initial premise is that our notion of the person, to be justifiable, must square with clinical experience. There is a sense in which this premise is trivial and a sense in which it will require more philosophical support than is possible here. Indeed, it raises fundamental issues in philosophy.

Of course it is true that how I think of the person must be in keeping with the reality of my clinical experience. It would be odd if I thought the patients I go to visit were not persons. How would I then think of them? What would mark the difference between these non-person patients and person patients? No, the situation is straightforward. My clinical work involves persons: human beings with whom I interact; people with whom I have relationships. I act and interact with people whom I regard as persons: I regard them as worthy of a certain sort of respect and a certain dignity. The ethical position I take with regard to my patients is constitutive of my regarding them as persons. It would be difficult to justify my conception of persons if it did not square with my everyday experience of working with people. Either my notion of what constitutes a person would have to change (in order to square with clinical experience), or I would have to re-evaluate clinical experience in the light of a new notion of the person.

At a deeper level this major premise brings into consideration hugely complicated issues. It is a statement about the relationship between metaphysics (our notion of the person) and reality (clinical experience). The further discussion of this relationship is beyond my scope. But there is room to make some observations about the nature of the relationship. It might be suggested, for instance, that metaphysics (our notion of the person) influences how we behave as doctors and health professionals. Think of a doctor whose notion of what it is to be a person allowed some to be ranked as superior and others as inferior. The opposite view would be that it is what we come across in the 
world (our clinical experience) that shapes how we think of people. On this view, my notion of what it is to be a person is simply a reflection of my experience of persons. In which case, rational reflection about personhood and the importance of metaphysics are devalued.

An alternative, middle route, is to take a Kantian view and to regard experience as involving some form of metaphysical conceptualisation. In other words, our experience of the world (in this case, the experience of clinical practice), for it to be the sort of human experience that it is, must involve thinking of things in a certain way. In a sense, this simply repeats the more mundane point: engaging with a patient in order to reach a diagnosis and determine appropriate treatment just is a human experience of a certain kind. It involves having a notion of what it is to be a human person, without which it would not be the type of experience that it is.

So, the major premise can be supported by taking the view that there is no gap between metaphysics and reality. Reality (clinical experience) involves metaphysics (our notion of the person) and vice versa. Inevitably, therefore, our notion of the person, to be justifiable, must square with clinical reality. Not only are questions about the relationship between metaphysics and the world raised by this major premise, however, so too are questions about justification.

I have previously discussed, using Wittgenstein, the problem of ultimate justification. ${ }^{1}$ Whilst that discussion now seems to me somewhat inchoate, the tenor of Wittgenstein's thoughts remains pertinent. $\mathrm{He}$ writes: "What people accept as a justification-is shewn by how they think and live"2, and: "If I have exhausted the justifications I have reached bedrock, and my spade is turned. Then I am inclined to say: "This is simply what I do"'. Elsewhere Wittgenstein writes: "What determines our judgment, our concepts and reactions, is not what one man is doing now, an individual action, but the whole hurly-burly of human actions, the background against which we see any action". ${ }^{4}$

The relevance of these quotations to my present argument is that they lend support to the philosophical method suggested by my initial premise. One way to find out whether our notion of the person is justifiable ("our judgment, our concepts and reactions") is to look to the hurly-burly of clinical experience. What is it in clinical practice that we simply do (ie without reflection) with respect to the people under our care that might show how we think of them as persons? Our notion of the person, to be justifiable, must square with how we "think and live" in the context of clinical practice. Grounding our metaphysical conception of the person in the hurly-burly of clinical practice makes the notion of the person as insecure (ie as lacking in objectivity) as the reality of that practice. So, whilst there is a philosophical debate to be had concerning the relationship between how things are in the world and our metaphysical conception of the world, nevertheless it is possible to support the premise that our notion of the person, to be justifiable, must square with clinical experience.

\section{The Locke-Parfit view of the person}

Locke describes the person thus: "a thinking intelligent being, that has reason and reflection, and can consider itself as itself, the same thinking thing, in different times and places; which it does only by that consciousness which is inseparable from thinking, and ... essential to it" . The person is the being with thoughts, intelligence, reason, reflection and consciousness. My "thinking conscious self" is bound up with my body, but - as Locke makes clear by considering what happens if a person's hand is cut off-it is the conscious self that is the person: "without consciousness there is no person". ${ }^{6}$ Locke makes an important distinction between "man" and "person". "Man" refers to the living human body, whilst "person" is tightly tied to consciousness. " "Consciousness" for Locke is "inseparable from thinking, and essential to it". ${ }^{6}$ As these quotations make clear, according to Locke, to be a person is to be a being with these psychological attributes.

This Lockean view of the person stands behind the views expressed by Parfit. ${ }^{8}$ For instance, Locke writes: "as far as this consciousness can be extended backwards to any past action or thought, so far reaches the identity of that person". . Parfit, like Locke, feels that a person's identity is maintained by the links which join that person's former state with his or her present state. In Parfit's terminology, what is meant by personal identity is covered by "psychological continuity", which involves "psychological connectedness". ${ }^{10}$ Just as Locke suggests, my personal identity now is linked to my personal identity last week by psychological continuity, which is maintained by memories, but also by beliefs, desires and by intentions. ${ }^{11}$ The consequence of these views is that personal identity is not what matters for Parfit, but psychological connectedness and/or continuity. ${ }^{12}$ Similar views are found in Hume: "Had we no memory, we never should have any notion of causation, nor consequently of that chain of causes and effects, which constitute our self or person". ${ }^{13}$

It is clear, therefore, that for Parfit, no less than for Locke (or Hume), to be a person is just to have certain psychological states. For Parfit it is the connections between these states that amount to the person; or, rather, there is (strictly speaking) no person, there are just bundles of connected memories, intentions, thoughts, sensations, beliefs and desires which achieve continuity. When we speak of persons we speak of no more than these continuing and connected psychological states.

\section{The situated-embodied-agent view of the person}

The alternative is the SEA view of the person. According to this view the person is best thought of as a human agent, a being of this embodied kind, who acts and interacts in a cultural and historical context in which he or she is embedded. Before 
considering the individual elements of this characterisation, it is worth noting the major distinction between this view and the LP view as marked by the differing attitude to psychological phenomena. In the SEA view psychological phenomena are properly understood only in a contextually embedded manner: they cannot be characterised independently of the situated context. According to the LP view, a person is constituted solely by psychological phenomena. This is a reductive view: the person, in essence, is no more than these particular connected mental states. But according to the SEA view, it is not possible to characterise psychological phenomena independently of an embedding context. So psychological phenomena are given a broad construal and the notion of the person is not reduced, but enlarged.

The SEA view has its most obvious roots in the works of Wittgenstein and Heidegger. No single philosopher, however, has defined it, although it emerges in the works of many. Charles Taylor has consistently put forward a picture of the self that allows characterisation in terms of the SEA view and-without suggesting that he would necessarily agree with my use of his work-I shall mainly use Taylor to describe the individual elements of this view. Thus I shall attempt to delineate the SEA view and bring out contrasts with the LP view.

\section{SITUATED PERSONS}

The notion of a situated self stresses context and the external factors that go to make up a person. We are situated among other things, in a familial, cultural and historical context. Taylor considers that a crucial fact about a self or person is that we are not selves in the way that we are organisms, "we are only selves insofar as we move in a certain space of questions, as we seek and find an orientation to the good" ${ }^{14}$ Taylor asserts that a basic condition of making sense of ourselves is, "that we grasp our lives in a narrative". ${ }^{15} \mathrm{He}$ uses this conception to counter the LP view of the person. For Taylor, human persons as selves, "exist only in a certain space of questions, through certain constitutive concerns. ... And what is in question is, generally and characteristically, the shape of my life as a whole" ${ }^{16}$ Taylor rejects the Parfitian notion that there are successive selves. Rather, "there is something like an a priori unity of a human life through its whole extent" ${ }^{17}$ Understanding persons involves an understanding of the narratives in which they are embedded.

MacIntyre also suggests that the notion of the unity of the self "resides in the unity of a narrative" ${ }^{18} \mathrm{He}$ suggests that "the histories of individual agents not only are, but have to be, situated, just because without the setting and its changes through time the history of the individual agent and his changes through time will be unintelligible". ${ }^{19}$ MacIntyre then emphasises "that what the agent is able to say intelligibly as an actor is deeply affected by the fact that we are never more (and sometimes less) than the co-authors of our own narratives". $\mathrm{He}$, too, criticises the LP view of personal identity.
According to MacIntyre, a person's story provides the requisite unity. ${ }^{21}$

\section{EMBODIED PERSONS}

Human persons are embodied and it is our bodies that place us in a historical context of time and place. In contradistinction to Locke, the concept of the person constitutively involves the "living human body". The notion of embodiment is emphasised by Taylor: "Our body is not just the executant of the goals we frame. ... Our understanding is itself embodied. That is, our bodily know-how, and the way we act and move, can encode components of our understanding of self and world.... My sense of myself, of the footing I am on with others, is in large part also embodied". ${ }^{22}$

Slors, too, contends that "the body can play the part that is usually ascribed to the immaterial ego; it can provide a deeper psycho-biographical unity..." . ${ }^{23}$ Slors makes use (again) of the notion of narrative to give a fuller account of psychological connectedness than that given by Parfit, becauseaccording to the narrative view-connectedness must also take into account the content of psychological states in virtue of which successive states have meaning. ${ }^{23}$ According to this view, whereas our psychological lives may be "gappy" (lacking in the ideal fluidity and coherence and occasionally disrupted by loss of consciousness), there is a "basic narrative ... represented by our consecutive perceptual contents". ${ }^{23}$ And, "successive perceptions acquire narrative coherence in virtue of the fact that we know them to be caused by one body's movements through a stable (not static) physical world with whose character and proceedings we are acquainted". So we must be situated in the world, of which we have an understanding, in order to make sense of our perceptions, which are bodily perceptions. Slors links the embodiment of persons to their situatedness through the notion of narrative. Moreover, he shows that the LP view needs to be expanded to take into account the reality of mental content, which acquires meaning (via narrative connectedness) within the context of the world in which the person, as body, perceives and moves. Hence, according to philosophers such as Slors and Taylor, the body cannot just be thought of as standing over against psychological states. It is inextricably involved in such states.

PERSONS AS AGENTS

The situated context involves human agency, because we act and interact with our surroundings in a way that can be interpreted humanly. Wilkes uses Aristotle to stress that the human being is an agent whose highest good is to live and do well. Thus: "We become the people that we are by choosing, deciding, acting; we have the responsibility for shaping ourselves, our characters, and our lives". ${ }^{26}$ Human beings are considered as active agents in the world, not as passive observers. An agent acts from a point of view and with a purpose.

It is these considerations that Taylor has in mind when he discusses agency. According to Taylor, we 
need to recover "an understanding of the agent as engaged, as embedded in a culture, a form of life, a 'world' of involvements, ultimately to understand the agent as embodied". ${ }^{25}$ By "engagement", Taylor implies that "the world of the agent is shaped by one's form of life, or history, or bodily existence". ${ }^{26}$ Thus, the notion of agency itself involves a sense both of the embeddedness and the embodiment of human persons.

\section{Ethical issues and dementia}

Both of the views just sketched of the person have implications for dementia. To take the LP view first, it seems that if a person's thoughts at one time are disconnected from his or her thoughts at another, for instance because of problems of memory, Locke and Parfit would claim that the person is, properly speaking, not one, but two. As Glover puts it: "The psychological unity of a life is not all-or-none. Memories or intentions can fade or disappear. I can be linked psychologically to other stages of my life to a greater or lesser degree. If I am hit in old age by senile dementia, perhaps nearly all my present self will have faded out". ${ }^{27}$ Locke said quite explicitly, comparing the "mad man" to the "sober man". "... if it be possible for the same man to have distinct incommunicable consciousness at different times, it is past doubt the same man would at different times make different persons" ${ }^{7}$ Parfit has suggested that as psychological connections are reduced "when there has been any marked change of character or style of life, or any marked loss of memory", someone might say, "It was not I who did that, but an earlier self". ${ }^{28}$

Such thoughts have practical relevance, as is seen in discussions of advance directives in dementia. ${ }^{29}$ The problem is to decide how much psychological continuity is necessary to ascribe any sense to personal identity. With these thoughts in mind, for instance, Hope accepts (with reluctance) the thought that a man before and after dementia is in fact a different person. ${ }^{30}$ Similarly, but going one step further, Buchanan suggests (whilst discussing disputes about advance directives) that the being with severe dementia, lacking the appropriate LP psychological continuities, is not a person at all. ${ }^{31}$ Clearly, such a view will have implications for other end-of-life decisions. Thus, Parfit writes: “... a person can gradually cease to exist some time before his heart stops beating. This will be so if the distinctive features of a person's mental life gradually disappear. This often happens. We can plausibly claim that, if the person has ceased to exist, we have no moral reason to help his heart go on beating, or to refrain from preventing this".

Whether talking about advance directives or end-of-life decisions, as the first of my minor premises suggests, the LP view of the person squares with only a circumscribed account of clinical experience. Say that a person, whilst still competent, has completed an unambiguous advance directive and then, once demented, the circumstances envisaged in the advance directive come to pass. The LP view leads to the conclusion that this is either a different person from the one who wrote the directive, or not a person at all. This is reasonable if personhood were solely equated with psychological continuity and connectedness. The SEA view suggests that there is more to being a person. Clinical experience suggests that the advance directive should be taken seriously. For the reality at the bedside suggests, in keeping with the SEA view, that this person today is continuous with and connected to the person who signed the directive, by embodiment and by the situatedness that embodiment entails.

It is instructive to consider slightly different cases. A man, having signed an advance directive on Monday, has a stroke on Tuesday. There is a sense in which on Tuesday he is a very different person from the one he was on Monday. But why say he is a completely different person? Is it that overnight the same body has acquired a different person? This seems an absurdly dualistic suggestion. No, his body (and the continuity it entails) is part of his personhood. Similarly, on account of his embodied, historical situatedness, he cannot be regarded as a non-person. His actions, however uncoordinated or pathetic, must also be interpreted in human terms since it is (inevitably) within the human context that he is situated.

Nothing here should suggest that decisions about this patient will be easy. It might be that, in consultation with his family (within which he is situated) it is decided to ignore his advance directive. Perhaps (contrary to his expectations on Monday concerning recovery from a stroke) there are indications that he will make a significant recovery. Perhaps he made the directive at the age of forty presuming that a stroke would only occur when he was seventy or eighty. But the decision concerning what should or should not be done does not hang on whether or not he is a person or a different person. That he is a person is precisely what makes the decision so difficult.

\section{Circumscribed account}

Concerning the end of life, there certainly are cases in which, as Parfit suggests, the person has ceased to exist before the heart has stopped beating. But will the judgment that the person has died merely be a judgment about the discontinuity and cessation of psychological states? Will there not be other cases, perhaps in dementia, where it will be cardiac arrest that definitively determines death? Or, if the non-demented, frail, elderly person slips into a comatose state as part of a pneumonia (losing psychological continuity), do we say she (the person) died as the coma came on (and when precisely?), or later when the heart stopped? This person surely dies when the heart stops. If this is denied in favour of saying the person died when the coma came on, then what if the person is young and normally fit, but is thrown into a coma by an accident or overwhelming infection? If we resuscitate the young person from the coma, will we then have to say that the person died and came alive again? 
The point is that the LP view of the person can offer only a circumscribed account of when death occurs and an account which is problematic precisely because of the circumscribed view of the person. Death remains problematic for the SEA view, but a broader appraisal is encouraged. Compare the coma of the frail, elderly person with that of the younger person. The natural clinical inclination might be to resuscitate the younger person but to hesitate before attempting to do so in the case of the older person. Is this a matter of ageism? There is another explanation, based on the broader SEA view of the person.

\section{Natural coda}

A person's coma is part of the person's history in which the person's life is embedded. If this history, or narrative, depicts a steady decline in function and increase in frailty, then the coma might seem a natural coda to the person's life. The last hours of that life, which might involve the arrival of the family to be by the bedside, even if psychological functioning seems absent, will still (clinically, legally and humanely) be judged to be the last hours of that person's life. And this makes sense on the SEA view, but not on the LP view, of the person. The narrative of the younger person, I am presuming, is wholly different. In this narrative the coma is a tragedy rather than a merciful release. This would only be ageist if I presumed that the narratives could only be this way. But, of course, it could be that the history and context in which these two people are embedded suggest that the older person should be actively resuscitated, whilst the younger person be given palliative care. Again, however, it is the SEA view of the person that provides the broader perspective and richer account of clinical experience. The LP view offers only a circumscribed (and thereby dangerous) account.

There are some ideas that cannot be encompassed by the LP view of the person. For instance, Dworkin accepts an "integrity-based theory of autonomy", which "focuses not on individual decisions one by one, but the place of each decision in a general program or picture of life the agent is creating and constructing, a conception of character and achievement that must be allowed its own distinctive integrity". ${ }^{33}$ On the basis of this theory, Dworkin suggests that we should respect "precedent autonomy": if we cannot respect a demented person's autonomy now, we can respect (if made clearly) the autonomous decisions arrived at before the dementia.

The general philosophical point is that precedent autonomy is predicated on the view, distinctly acknowledged and accepted by Dworkin, that personal identity survives serious dementia. ${ }^{34}$ If this were not the case, then the integrity view would lose its purchase. But the suggestion that personal identity survives serious dementia is not one compatible with the LP view of the person. The integrity view of autonomy, in keeping with the SEA view of the person, more richly stresses the importance of a person's agency and history.
The view of the person, it seems to me, will come into play in connection with a number of ethical issues relevant to dementia. For instance, in the gamut of issues that arise for carers, such as whether or not the person should be "placed" into long term residential care, the SEA view will always provide a richer reflection of the issues than the LP view. But I shall end by considering "best interests", the basis upon which many decisions concerning people with dementia must be made.

The UK government's green paper on the reform of the Mental Health Act suggests that in determining a person's best interests regard should be given to: (1) the ascertainable past and present wishes and feelings of the person and the factors the person would consider if able to do so; (2) the need to permit and encourage the person to participate in what is done or decided for him or her; (3) the views of others concerning the person's wishes and feelings, and (4) whether ends can be achieved in a manner less restrictive of the person's freedom of action. ${ }^{35}$

Now, in the case of someone with a fairly severe dementia, the LP view of the person would lead only to difficulties using these criteria. Locke and Parfit would have to say this was simply not the same person, or not a person at all. Hence, much contained in these criteria would seem at least problematic, if not nonsensical. Contrariwise, these criteria not only spell out what most would accept as good practice in the assessment of best interests, but also embody the insights of the SEA view of the person. For these criteria suggest: first, a presumption in favour of the person; secondly, that the person is situated in a history, which is both physical, emotional, conative and cognitive; thirdly, that the person is embedded in a context of care, which might be familial, social or professional; and, finally, that the person is an agent and that the person's agentive capabilities (even in severe dementia) should be "encouraged". Once more, the SEA view of the person, over against the circumscribed nature of the LP view, provides the richer account, which squares more readily with clinical experience.

\section{Conclusion}

Having supported the premises of my argument, therefore, I conclude that the SEA view of the person, over against the LP view, is more justifiable. At the start I asked whether dementia destroys the person as it destroys the brain. As we have seen, according to the LP view this is inevitably going to be the case once the brain cannot sustain psychological continuity and connectedness. On the other hand, the SEA view holds out the possibility that the person might survive into severe dementia. For whilst the person's agency might be whittled away (albeit gestures and behaviour can act as continuing manifestations of agency), if personhood is embedded in the individual's life-history and engagement with others, as well as in his or her bodily form, then it makes sense still to talk of the person even in severe dementia.

I alluded in my introduction to the philosophical and practical implications of my argument. One 
philosophical implication of this argument concerns the implied externalist view of the mind. Such a view suggests that thoughts, memories, intentions and the like cannot be considered as mere inner, private occurrences. In order to be meaningful, they must be shareable in the external world - the very world in which persons are situated. Having gestured at this idea, I cannot pursue it, but a sustained account of this type of view can be found in Luntley. ${ }^{36}$

The practical implication is that, as my argument has shown, the conceptual view taken is likely to affect how we are prone to care for people with severe dementia. Whilst I would wish to avoid his social constructionism, my emphasis on the socially situated nature of personhood aligns me with the work of Kitwood. ${ }^{37}$ His work has had the practical effect of alerting us to the potentially malignant nature of the social environment. At the same time he has encouraged us to see the potential we have to enhance the personhood of people with even severe dementia. The SEA view argues in favour of treating people with severe dementia with as much care and compassion as we treat other persons. Any undermining of their personhood becomes an undermining of the whole concept of personhood; that is, an undermining of our own standing as persons amongst persons.

\section{Acknowledgements}

I would like to thank Dr Stephen Louw for kindly reading and commenting on this paper. The paper has also benefited from the comments of Professor Gillon, Dr David Lamb and another anonymous referee. Its inadequacies remain solely mine.

Dr fulian C Hughes, PhD, MA, MRCPsych, is a Consultant in Old Age Psychiatry at Newcastle General Hospital, an Honorary Clinical Lecturer at Newcastle University and a Research Fellow at The Oxford Centre for Ethics and Communication in Health Care Practice (ETHOX).

\section{References}

Hughes J. Ultimate justification: Wittgenstein and medical ethics. Fournal of Medical Ethics 1995;21:25-30.
2 Wittgenstein L. Philosophical investigations. Oxford: Blackwell, 1968: \$325.

3 See reference $2: \$ 217$

4 Wittgenstein L. Zettel. Oxford: Blackwell, 1967: \$567.

5 Locke J. An essay concerning human understanding (1690). Woozley AD, ed. Glasgow: William Collins/Fount, 1964: 211.

6 See reference $5: 218$.

7 See reference 5: 217

8 Parfit D. Reasons and persons. Oxford: Oxford University Press, 1984: 205-7.

9 See reference 5: 212 .

10 See reference 8: 206

11 See reference $8: 205$.

See reference $8: 262$.

13 Hume D. A treatise of human nature (1739). Macnabb DGC, ed. Glasgow: Fontana/Collins, 1962: 311

14 Taylor C. Sources of the self: the making of the modern identity. Cambridge: Cambridge University Press, 1989: 34.

15 See reference 14: 47 .

16 See reference 14:50.

17 See reference $14: 51$

18 MacIntyre A. After virtue: a study in moral theory [2nd ed]. London: Duckworth, 1985: 205.

19 See reference 18: 206-7.

20 See reference 18: 213 .

21 See reference 18: 217

22 Taylor C. Philosophical arguments. Cambridge, Mass: Harvard University Press, 1995: 170-1.

23 Slors M. Two conceptions of psychological continuity. Philosophical Explorations 1998;1:61-80.

24 Wilkes KV. Real people. Personal identity without thought experiments. Oxford: Clarendon Press, 1988: 213.

25 See reference 22: 61-2.

26 See reference 22: 62 .

27 Glover J. I: the philosophy and psychology of personal identity. Harmondsworth: Penguin, 1988: 102.

28 Parfit D. Personal identity. Philosophical Review 1971;80:3-27.

29 Dresser R. Advance directives, self-determination, and personal identity. In: Hackler C, Moseley R, Vawter DE, eds. Advance directives in medicine. New York: Praeger, 1995: Advance 70 .

30 Hope T. Personal identity and psychiatric illness. In: Phillips Griffiths A, ed. Philosophy, psychology and psychiatry. Cambridge: Cambridge University Press, 1994: 131-43.

31 Buchanan A. Advance directives and the personal identity problem. Philosophy and Public Affairs 1988;17:277-302.

32 See reference 8: 323 .

33 Dworkin R. Autonomy and the demented self. The Millbank Quarterly 1986;64(suppl 2): 4-16.

34 Dworkin R. Life's dominion: an argument about abortion and euthanasia. London: Harper Collins, 1993: 237.

35 Department of Health. Reform of the Mental Health Act 1983. Proposals for consultation. London: HMSO, 1999: 35.

36 Luntley M. Contemporary philosophy of thought: truth, world, content. Oxford: Blackwell, 1999.

37 Kitwood T. Dementia reconsidered: the person comes first. Buckingham: Open University Press, 1997. 